\title{
Weight Bias in Educational Settings: a Systematic Review
}

\author{
Sarah Nutter ${ }^{1} \cdot$ Alana Ireland $^{1} \cdot$ Angela S. Alberga $^{2} \cdot$ Isabel Brun $^{1} \cdot$ Danielle Lefebvre $^{1} \cdot \mathrm{K}$. Alix Hayden ${ }^{3}$. \\ Shelly Russell-Mayhew ${ }^{1}$
}

Published online: 28 February 2019

(C) Springer Science+Business Media, LLC, part of Springer Nature 2019

\begin{abstract}
Purpose To conduct a systematic literature review of empirical peer-reviewed published studies on the prevalence of weight bias among students, pre-service, and in-service teachers and its impact on the educational experiences and health of students from kindergarten to postsecondary settings.

Methods Keywords were searched on three main concepts, (i) weight bias/stigma, (ii) obesity/overweight, and (iii) education, within eight databases. Our search yielded 8323 individual records, of which 45 studies satisfied our inclusion criteria.

Results Most studies were conducted in K-12 school settings $(n=41)$, were quantitative in design $(n=37)$, and used student samples $(n=18)$. Weight bias is prevalent in educational settings, among peers at school as well as preservice and in-service teachers, and negatively impacts students' health and educational experiences.

Conclusion These results highlighted the impact of weight bias in creating inequity for students with obesity as well as several underexamined areas, such as weight bias in postsecondary settings and attitudes among teachers and pre-service teachers. Innovative strategies to address weight bias in educational settings are needed.
\end{abstract}

Keywords Weight bias $\cdot$ Education $\cdot$ Obesity $\cdot$ Wellness $\cdot$ Stigma $\cdot$ Discrimination

This article is part of the Topical Collection on The Obesity Epidemic: Causes and Consequences

Sarah Nutter

snutter@ucalgary.ca

Alana Ireland

adirelan@ucalgary.ca

Angela S. Alberga

angela.alberga@concordia.ca

Isabel Brun

ibrun@ucalgary.ca

Danielle Lefebvre

dclefebv@ucalgary.ca
K. Alix Hayden

ahayden@ucalgary.ca

Shelly Russell-Mayhew

mkrussel@ucalgary.ca

1 Werklund School of Education, University of Calgary, 2500 University Drive NW, Calgary, AB T3C 0T1, Canada

2 Department of Health, Kinesiology, and Applied Physiology, Concordia University, 7141 Sherbrooke Street West, Montreal, QC H4B 1R6, Canada

3 Libraries and Cultural Resources, University of Calgary, 2500 University Drive NW, Calgary, AB T3C 0T1, Canada 


\section{Introduction}

For over 50 years, researchers have documented weight bias, ${ }^{1}$ known as the negative attitudes and beliefs and discrimination toward individuals who live with obesity [1-3]. Weight bias in kindergarten to grade $12(\mathrm{~K}-12)$ schools most often manifests as children and adolescents with obesity being victims of direct forms of aggression such as verbal teasing/bullying (e.g., verbal harassment, name-calling, fat jokes), physical bullying (e.g., hitting, pushing, kicking, shoving), or indirect forms like relational bullying (e.g., social exclusion, being the subject of rumors) due to their body weight [4-6]. For children and adolescents, schools are a common setting for experiences of weight bias, as peers, teachers, and other school professionals can also hold negative attitudes and beliefs about individuals with obesity $[4,7]$. Adolescents living with obesity have reported that the school context is the most common place for weight-based teasing to occur [8] and that they are much more likely to be victims of bullying than their counterparts with "normal" weights $[9,10]$. In the same period of time that childhood obesity has come to be labeled an epidemic (i.e., the last 40 years), weight bias against children has increased dramatically by $41 \%$ [11].

Educational settings have often been seen as important sites to "prevent" or "combat" obesity [12]. However, actions taken in efforts to improve the health of students may be misleading, misguided, and even potentially harmful [12]. Weight bias in schools begins early in childhood and becomes more prevalent in adolescence, with the largest children at the highest risk of being bullied [7] regardless of gender, race, social skills, or academic achievement [13]. The impact of weight bias extends through from grade school to postsecondary educational settings [14]. Being on the receiving end of weight bias has serious psychosocial and physical consequences in children and youth including increased risk of depression, anxiety, social isolation, substance use, suicidal thoughts, poor body image, low self-esteem, unhealthy eating behaviors, binge eating, decreased physical activity, and worsening of obesity $[2$, 15]. Despite the serious consequences of weight bias, students with obesity have reported that policies intended to create safe environments in educational settings have not been applied or enforced in relation to weight-based discrimination [16]. While weight bias continues to be a problem in educational spaces, the literature on the topic must be synthesized to help guide future interventions, policies, and practices to address weight bias in educational settings.

The purpose of this systematic review was to synthesize the available evidence on the prevalence of weight bias and its

\footnotetext{
${ }^{1}$ We acknowledge that multiple terms are used in this area of research, including weight-based victimization, weight-based teasing, weight-based bullying, and weight bias. In this paper, our use of weight bias is intended to be an umbrella term for these concepts.
}

impact on the educational experiences and the health of students in K-12 and postsecondary settings. While similar previous reviews of weight bias literature have been conducted, these reviews have focused on the broad nature of weight bias experienced by children and youth, not limited to an educational setting $[17,18]$, how children and youth cope with weight bias in physical education settings specifically [19], and associations between childhood obesity and academic achievement [20]. The current review adds to this literature by providing a review of original research specific to the occurrence of weight bias in educational settings, but broadens the review to all educationally based research, rather than research conducted solely within physical education. Specifically, this review aimed to examine (1) the prevalence of weight bias within educational settings, (2) the impact of weight bias within these settings on the health or peer relationships of students, (3) teachers' or pre-service teachers' attitudes and beliefs about students with obesity, and (4) weight bias reduction interventions conducted with students, teachers, or pre-service teachers in educational settings.

\section{Method}

We followed the systematic review protocol outlined in the Cochrane Handbook for Systematic Reviews of Interventions [21]. We report our findings in accordance with the PRISMA (Preferred Reporting Items for Systematic Reviews and MetaAnalyses) [22] statement presented in Fig. 1.

\section{Data Sources}

A health sciences librarian (K.A.H.) developed the search strategy based on three main concepts: (i) weight bias/stigma, (ii) obesity/overweight, and (iii) education. Keywords were generated for each of the three main concepts by reviewing subject indexing and key terms, and by reviewing search strategies from similar systematic reviews in weight bias literature $[2,23-25]$. The search strategy was pre-tested to ensure that relevant known studies were retrieved. Keywords were the same for each database, and subject headings were determined by the controlled vocabulary for each database. The MEDLINE search strategy can be found in the Appendix.

The search strategy was limited to English and from the publication date of 2000 onwards. Searches were conducted in eight databases (OVID databases: Medline, EMBASE, PsycINFO, Cochrane Central Register of Controlled Trials; and EbscoHost databases: CINAHL SocINDEX, Education Research Complete, ERIC). The initial search was conducted in December 2016, and was updated in May 2018. Studies were included if they were original research articles that aimed to address our research objectives outlined above and were published in English. Commentaries, editorials, literature reviews, letters, conference abstracts, theses, and gray literature 


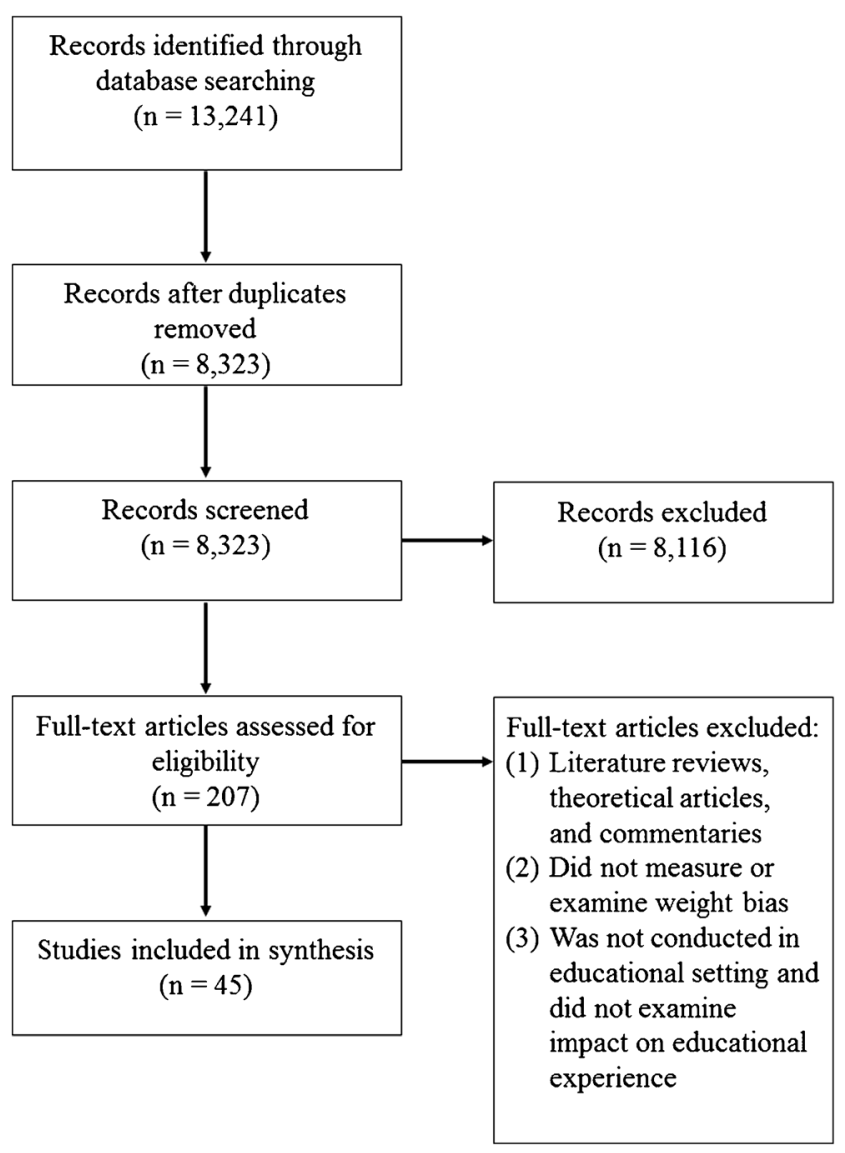

Fig. 1 PRISMA diagram overview selection of studies for review

were excluded. Furthermore, articles were excluded if (i) they examined the effects of an obesity prevention program in schools where weight bias was not measured, (ii) research conducted with school-aged or postsecondary samples that investigated only the prevalence of weight bias as a proxy for the prevalence of weight bias in the general population rather than with the purpose of examining the impact of these attitudes on educational experiences, and/or (iii) the article did not examine educational attainment based on body weight or was not related to weight bias within an educational setting.

The search yielded a total of 13,241 abstracts. After the removal of duplicates $(n=4918)$ and inter-rater training, two authors (S.N. and A.I.) independently screened the remaining 8323 titles/abstracts and reached consensus through discussion, when required. Given the large quantity of records identified through the search, two research assistants (I.B. and D. L.) were recruited and trained to assist with the remaining phases of the screening process. The 207 papers that met the inclusion criteria in the title/abstract screening were then reviewed in full text for eligibility (by S.N. and I.B. or A.I. and D.L.). This phase resulted in 45 articles selected to be included in the review. Working independently, all four reviewers (S.N. and I.B. or A.I. and D.L.) analyzed and summarized the 45 studies, which were verified by S.N and A.I. for the final inclusion.

\section{Results}

\section{Study Characteristics}

Study characteristics are described in Table 1 . Of the 45 papers included in this review, 18 reported samples of students (i.e., $\mathrm{K}-12$, postsecondary), 16 were samples of teachers, and 11 described samples of pre-service teachers (i.e., postsecondary Bachelor of Education students). Regarding educational settings, 41 papers examined weight bias in the K-12 setting, 3 were conducted in a postsecondary setting, and 1 paper was a retroactive study with adults on past experiences in K-12 physical education (PE). There were 37 quantitative studies and 8 qualitative studies. The majority of studies examined negative attitudes toward students with obesity (i.e., weight bias) and its prevalence among peers, teachers, and preservice teachers $(n=28)$. The remaining studies examined the impact of weight-based victimization on student wellbeing $(n=5)$, the effectiveness of weight bias reduction interventions $(n=6)$, students' preferred sources of support for weight bias at school $(n=2)$, teacher behavior toward students with obesity $(n=2)$, and student experiences with weight bias in K-12 physical education (PE) classes $(n=2)$.

\section{K-12 and Postsecondary Student Samples $(n=18)$}

Research with student samples examined the prevalence and impact of weight bias, preferred supports for student victims of weight bias, experiences specific to PE, and a school-based intervention aimed to reduce weight bias among children and adolescents. Papers included in this section represent research that investigated the impact of weight bias on students in a $\mathrm{K}-12$ or postsecondary educational setting.

Prevalence of Weight Bias Eight studies examined the prevalence of weight bias with samples of children and adolescents [7, 14, 26-31]. The results of these studies suggest that children or adolescents with obesity are more likely to be bullied than students without obesity $[13,29]$ and that students with obesity are likely to experience threats, physical victimization, and social exclusion in addition to weight-based teasing [7, 26]. Among a sample of adolescents with obesity, $71 \%$ indicated experiencing weight-based victimization (e.g., teasing) at school within the previous year [30], which is consistent with a sample of adolescent peers, of whom 85-92\% reported witnessing weight-based teasing at school [7]. Research examining peer relations and friendship networks demonstrated that, as body weight increases, children and youth are less likely to be identified as friends [27], are perceived as less popular, more sensitive, less attractive, and less athletically skilled [31], and that these differences do not differ for students based on racial or ethnic diversity [28]. 
Table 1 Characteristics of Studies that Met the Inclusion Criteria

Ref. Authors Study purpose Sample $\quad$ Methods/measures $\quad$ Summary of findings

No.

Student samples

[7] Puhl et al., 2011

$\begin{array}{ll}\text { Investigated adolescent } & n=1555 \\ \text { perceptions and } & \text { Grades 9-12 } \\ \text { observations of } & \\ \text { weight-based bullying } & \\ \text { in school } & \end{array}$
[8] Puhl and
Luedicke,
2012

\author{
Examined how $\quad n=394$ \\ adolescents cope with Grades 9-12 \\ weight-based teasing \\ at school
}

[13] Lumeng et al., 2010

[26] Bacchini et al., 2015

\author{
Examined relationship $\quad n=821$ \\ between obesity and Grades 3, 5, 6 \\ being bullied \\ Investigated associations $n=947$ \\ between BMI and Ages 6-14 \\ types of bullying \\ victimization
}

[27] Crosnoe et al., 2008

[28] Cunningham et al., 2012

[29] Kahle and

Peguero, 2017
Examined the role of body size in social networks
Influence of race/ethnicity on peer relationships of youth with obesity

Investigated how gender, $n=7142$

race, ethnicity, and Grades 6-10 weight related to

school bullying

$n=2728$

Grades 7-12

$n=10,723$ Grades $7-12$
*Observations of weight-based teasing and bullying

*Fat Phobia Scale
Participants responded to items querying:

*BMI

*Teasing and bullying incidents *Bullying locations *Affective responses to bullying

*Coping strategies *School responses to bullying

*BMI

* Perceptions of Peer Support Scale

*Body mass index (BMI)

*Revised Olweus Bully/Victim Questionnaire

*10 friendship nominations *BMI

*10 friendship nominations *BMI

Participants responded to items querying:

*Perceived classmate support

*Bullying experiences

*BMI

*Race/Ethnicity

[30] Puhl et al., 2013 Investigated the settings $n=361$ and forms of weight Ages 14-18 bullying
Participants responded to items querying:

*BMI

*Experiences with weight bullying
Observations of weight-based bullying were reported by $85-92 \%$ of participants, with $58-69 \%$ of participants reporting observing these situations sometimes, often, or very often. The most common types of bullying reported were teasing, name-calling, and teasing during physical activity. Other types of bullying reported were avoidance, teasing in the cafeteria, exclusion from social activities, and being the target of rumors

$40-50 \%$ of students who reported weight-based bullying indicated it makes them feel sad, depressed, angry, and negative about their body. Girls reported a significantly more negative affect in response to weight-based teasing (vs. boys). Weight teasing in PE was associated with avoidance coping strategies among girls (but not boys)

Children with obesity were more likely to be bullied

Chi-square analyses revealed that participants with severe obesity were more frequently involved in bullying and received multiple types of victimization (e.g., physical, social exclusion, teasing, name-calling)

As BMI increased, the likelihood of receiving friendship nominations decreased, especially for girls

Participants with obesity were selected as a friend less often (vs. youth without obesity), with no racial/ethnic differences

Female participants with overweight/obesity were more likely to experience bullying. Male participants with underweight or overweight/obesity were more likely to experience bullying

Most participants (71\%) reported weight bullying at school at least "sometimes" in the last year. Participants reported weight bullying by peers and friends most commonly. Frequently reported types of bullying were verbal, relational, cyberbullying, and text messages, with physical bullying reported least often. Most common settings included peer groups, classrooms, 
Table 1 (continued)

Ref. Authors Study purpose Sample $\quad$ Methods/measures $\quad$ Summary of findings

No.

[31]

$\begin{array}{lll}\text { Zeller et al., } 2008 & \begin{array}{l}\text { Examined peer } \\ \text { relationships of } \\ \text { students with obesity }\end{array} & n=90 \\ & \text { Ages 8-16 }\end{array}$

[32] Lampard et al., 2014
Examined the consequences of weight-based teasing at school

$n=2793$

Grades 6-12

[33] Li and Rukavina, Explored the nature of $\quad n=47$ 2012 weight-related teasing Ages 11-19 in PE programs

[34] Li et al., 2012 Investigated adolescent
coping strategies for
weight-based teasing $n=47$ Age 11-19

[35•] Phelan et al., 2015

\section{Assessed the relationship between internalized weight bias and} stress-related factors $n=4732$ First-year medical students from 49 US schools

$$
* \text { Weic }
$$

*Weight Implicit Associations Test (IAT) or the IAT for another stigmatized group

*State Self-Esteem Scale

*Physical health fatigue

*Study Social Support Survey

*Brief COPE measure

*Anti-Fat Attitudes Scale

*Everyday Discrimination Scale

*Focus groups *Qualitative interviews

weight-related issues 21 grade 4-6 students, affecting students and 12 school staff, identified strategies to 21 parents address issues at a

school level
[37] Puhl et al., 2013 Explored students' $n=361$ preferred bullying Ages 14-18 intervention strategies

[38] Wiltshire et al., Investigated peer $\quad n=29$ 2017 influence on PE Ages 13-14

Participants responded to items querying: at school

*Preferences for responses to weight bullying

*Focus groups
*Qualitative interviews

hallways, cafeteria, and PE settings

Children with obesity were nominated as a best friend less often, were described as more sensitive, isolated, athletic, and less attractive, and displayed less leadership (vs. children without obesity)

Approximately one-fourth of participants reported weight-related teasing at school. Teasing at school was associated with lower self-esteem and greater body dissatisfaction in girls, and greater depressive symptoms in boys

Participants reported experiencing multiple forms of weight teasing in PE classes. Participants indicated they felt hurt and that teachers lacked awareness of weight-related teasing

Participants reported using multiple strategies to deal with weight teasing, including self-protection, compensation, confrontation, seeking social support, avoidance/psychological disengagement, losing weight, and stress reduction

Students with overweight/obesity reported poorer overall health, body esteem, and loneliness, and were more likely to use alcohol or drugs to cope with stress. Female students with overweight/obesity had significantly worse social support (vs. male and female students without overweight/obesity)

Participants identified weight-related teasing and body dissatisfaction as important issues and that prevention programs need to address weight bias. Multiple specific recommendations for school staff were provided

*Experiences with weight bullying

*Perceived social support
$64 \%$ of participants reported past experiences with weight bullying. Participants indicated bullying intervention, in order of preference, as being by friends, peers, teachers, $\mathrm{PE}$ teachers/coaches, and parents Participants believed having overweight/obesity is associated with health risks and social risks. Participants indicated engaging in efforts to build social capital, including engaging in exercise to burn calories 
Table 1 (continued)

\begin{tabular}{|c|c|c|c|c|c|}
\hline $\begin{array}{l}\text { Ref. } \\
\text { No. }\end{array}$ & Authors & Study purpose & Sample & Methods/measures & Summary of findings \\
\hline & $\begin{array}{l}\text { Sykes and } \\
\text { McPhail, } 2008\end{array}$ & $\begin{array}{l}\text { Explored experiences } \\
\text { with PE for } \\
\text { individuals who have } \\
\text { identified as } \\
\text { overweight/obese }\end{array}$ & & & $\begin{array}{l}\text { Participants described experiences } \\
\text { with PE impaired body } \\
\text { acceptance and were among the } \\
\text { most explicit experiences with } \\
\text { weight stigma in their lives }\end{array}$ \\
\hline$[40]$ & $\begin{array}{l}\text { Haines et al., } \\
2006\end{array}$ & $\begin{array}{l}\text { Evaluated the } \\
\text { effectiveness of a } \\
\text { weight-based teasing } \\
\text { intervention }\end{array}$ & $\begin{array}{l}n=120 \\
\text { Grades 4-6 }\end{array}$ & $\begin{array}{l}\text { Intervention: } \\
\text { Two schools assessed; one } \\
\text { received the multi-faceted } \\
\text { intervention with individual, } \\
\text { environment, and family } \\
\text { components } \\
\text { *Teasing by others }\end{array}$ & $\begin{array}{l}\text { The percentage of participants who } \\
\text { reported being teased decreased } \\
10 \% \text { in the intervention school, } \\
\text { with no differences in body } \\
\text { satisfaction, thin-ideal } \\
\text { internalization, and unhealthy } \\
\text { weight control behaviors }\end{array}$ \\
\hline
\end{tabular}

Teacher samples

*Body Satisfaction Scale

*Thin-ideal internalization

*Unhealthy weight control

behaviors

$\begin{array}{cc}\text { [14] Burmeister et al., } & \begin{array}{l}\text { Impact of weight bias in } \\ \text { graduate school } \\ \text { admissions }\end{array}\end{array} \quad \begin{gathered}97 \text { psychology graduate } \\ \text { applicants, }\left(M_{\text {age }}=25.35\right)\end{gathered}$

*BMI

*Graduate Record Examination scores

* Grade Point Average

*Coded letters of recommendations

$\begin{array}{ccc}\text { [41] } & \text { Fontana et al., } & \begin{array}{c}\text { Examined PE } \\ \text { teacher/pre-service } \\ \text { teacher attitudes } \\ \text { toward students with } \\ \text { obesity } \\ \end{array} \\ & \begin{array}{c}\text { Evaluated PE faculty } \\ \text { attitudes toward PE } \\ \text { postsecondary } \\ \text { students }\end{array}\end{array}$

$n=196$

47 PE teachers $\left(M_{\text {age }}=37.07\right)$

149 PE pre-service teachers

$\left(M_{\mathrm{age}}=21.15\right)$

94 PE faculty members

$\left(M_{\mathrm{age}}=47.83\right)$

*Anti-Fat Attitude Scale

*Perception of Obese Students by Physical Education Teachers

Questionnaire

*Weight IAT

*Weight IAT

*Anti-Fat Attitudes Scale

*Perceptions of educators with obesity
[43] Greenleaf and Weiller, 2005

[44•] Kenney et al., 2015

[45] Kenney et al., 2017

[46] Lau et al., 2018

[47] Martinez-Lopez et al., 2017
Examined weight bias in PE teachers, perceptions of performance ability, and problems of youth with obesity

Investigated relationship between child weight gain and perceptions of academic ability

Teacher ratings of 3362 students, grades 5-8

\section{Examined teacher perceptions of the academic challenges of students with obesity}

\section{2 teachers}

Assessed weight bias of $n=200$ teachers

Ages 23-60

100 PE teachers,

100 non-PE teachers

Examined PE teachers perceived self-efficacy toward including students with overweight/obesity
471 PE teachers, ages 21-63 *Self-Efficacy Questionnaire

*Perceptions of youth obesity

*Physical Education

Questionnaire
Higher BMI was associated with fewer post-interview offers of admission, particularly for female applicants

Results suggested no explicit weight bias from self-report questionnaires, but strong implicit weight bias

Participants had positive attitudes toward accepting postsecondary students with obesity to PE programs, but did not believe they were positive role models for children and youth. Weight bias was associated with stronger disapproval of PE teachers with obesity

Results indicated moderate weight bias, higher expectations for students without obesity (vs. with obesity), and strong endorsement of obesity as a concern that schools should be involved in

*BMI over time

*Standardized reading and math scores

*Teacher ratings of reading and math

*Qualitative interviews

*Weight IAT

Increasing BMI from grades 5-8 was associated with a significant decrease in teacher ratings of reading ability (for girls) and math ability (for boys)

Teachers believed that students with obesity are likely to experience academic difficulties, due to low self-esteem, poor nutrition, increased screen time, and decreased activity

Younger participants and male participants, as well as PE teachers, had stronger implicit weight bias

Participants with higher perceived self-efficacy were more sensitive to the needs of students with overweight/obesity and held less bias toward them 
Table 1 (continued)

Ref. Authors Study purpose Sample $\quad$ Methods/measures $\quad$ Summary of findings

No.

[48] Peterson et al., Investigated PE teacher 2012 expectations of abilities of students with obesity

[49•] Puhl et al., 2016 Explored educator perspectives related to weight bullying policies in schools

[50] Shackleton and Campbell, 2014

Investigated teacher perceptions of student ability

240 educators $\left(M_{\mathrm{age}}=45.17\right)$

Responded to items querying:

*Support for policies to address weight bullying and eating disorders

*Perspectives about weight bullying

*Perspectives about eating behaviors

3113 clusters of teacher ratings *Teachers' ratings of math and of students for math and reading abilities reading at student age 7

*BMI

*British Ability Word Reading Test

[51] Wilson et al., 2015

\author{
Explored teachers' \\ perceptions of \\ children with obesity \\ vs. asthma
}

[52] Doolittle et al., 2016

\author{
Explored PE teachers' \\ perspectives on \\ students with obesity \\ in PE
}

[53] Peterson et al., 2012

\author{
Examined how a \\ student's weight and \\ gender impact PE \\ teacher responses to \\ bullying
}

140 teachers

Health Conditions Attitude Questionnaire (for obesity and asthma)

9 PE teachers

$162 \mathrm{PE}$ teachers and coaches

*Fat Phobia Scale
[54] Hague and White, Evaluated the 2005

[55] McVey et al., 2009 effectiveness of a Web-based weight bias intervention

\section{Evaluated the}

effectiveness of a Web-based weight bias intervention
258 in-service and pre-service teachers $\left(M_{\text {age }}=26.8\right)$

$n=167$

78 teachers, 89 public health practitioners
*Qualitative interviews

Intervention included information on the multiple factors of obesity

*Anti-Fat Attitudes Test

Intervention:

Information about factors that influence body image and strategies to address weight bias in schools

Participants responded to items querying knowledge and efficacy to address weight bias
Participants expected students without overweight to have higher abilities than students with overweight. Participants attributed the lack of physical activity and poor eating habits as contributing to physical ability differences for female students, but not for male students. Participants associated more positive adjectives to students without overweight (vs. with overweight)

Participants indicated that weight bullying and disordered eating were problems at their schools and support improved prevention and intervention efforts

After controlling for cognitive test scores, children without obesity were significantly more likely to be rated as having above-average ability in reading (vs. children with obesity)

Findings suggested that teachers believed children have control over their body weight, that children would use their weight as an excuse in the classroom, and that children with asthma have higher peer acceptance (vs. children with obesity)

Three themes emerged related to students with obesity: (1) being different, (2) having specific concerns related to PE, and (3) being a challenge and responsibility to $\mathrm{PE}$ teachers

Participants who viewed a photo of a female student were more likely to intervene for relational bullying when the victim had overweight (vs. without overweight). There were no significant differences in the likelihood of responding to bullying for participants who viewed a photo of a male student

Weight bias decreased in the intervention group (vs. control group) between pre-test and posttest/follow-up

The results indicated that the intervention improved participants' knowledge related to content, and that public health practitioners experienced an increase in perceived efficacy to address weight bias in schools. Participants also reported increased awareness about how 
Table 1 (continued)

Ref. Authors Study purpose Sample Methods/measures Summary of findings

No.

Pre-service teacher samples

[56] Glock et al., 2016 Examined implicit weight bias, explicit weight bias, and motivation to respond without prejudice

[57] Greenleaf et al., Investigated students' 2008 weight bias, perceptions of the schools' role in addressing obesity

$$
\begin{aligned}
& 51 \text { pre-service teachers } \\
& \left(M_{\text {age }}=21.12\right)
\end{aligned}
$$

$n=430$

212 PE pre-service teachers, 218 non-PE pre-service teachers, ages $18-45$
* Implicit Priming Task

*Attitudes toward Obesity and Overweight Persons Questionnaire

* Internal and External Motivation to Respond without Prejudice Scale

*Modified Fat Stereotypes Questionnaire

*Perceptions of Physical Education Questionnaire
[58] Lynagh et al., 2015

[59] Muller et al., 2017

[61] Readdy and
Wallhead 2016

[62] Tkachuk and Russell-Mayhew, 2017
Assessed the weight bias

of pre-service

PE-specialist and non-specialist teachers $n=239$

177 non-specialist pre-service teachers

62 PE specialist pre-service teachers
*Weight IAT

*Anti-Fat Attitudes Questionnaire *Beliefs about Obese People Scale *Perceptions of Youth Obesity Physical Education Questionnaire *Expectations of Overweight Youth Questionnaire

Participants responded to items querying:

*Academic performance

*Reading competency

*Social skills

*Anti-Fat Attitudes Scale

*Weight IAT

*Body Esteem Scale

*Physical Identity

*Social Dominance Orientation Scale

*Weight IAT

*Anti-Fat Attitudes Scale

*Coded classroom observations among pre-service teachers and the impact of attitudes on feedback to students undergraduate students

$\left(M_{\mathrm{age}}=18.49\right.$ and 21.8)

$$
\left(M_{\text {age }}=23.6\right)
$$

weight bias influences their teaching practices and the impact of these practices on student body image

Results suggested a pro-thin implicit bias and explicit dislike of students with obesity as well as fear of fat. Participants perceived greater academic achievement in students with obesity, and had strong motivation to respond without prejudice

Findings indicated that most participants $(83 \%)$ endorsed weight stereotypes. PE specialists rated students being normal weight as more important (vs. non-PE specialists). Stronger endorsement of weight stereotypes was associated with belief that PE teachers should educate parents on childhood obesity

All participants reported strong implicit weight bias, moderate explicit weight bias, and beliefs that children with obesity are unhealthy. PE specialist pre-service teachers had significantly lower expectations for children with obesity (vs. non-specialist pre-service teachers)

Participants regarded students with obesity as performing better academically (vs. students without obesity), but did not differ on perceived social skills for students with and without obesity

PE students rated physical identity as more important, had greater implicit weight bias, and had higher scores on the Willpower subscale of the Anti-Fat Attitudes Scale (vs. psychology students)

Participants with strong implicit weight bias gave more feedback to students (vs. participants with moderate/low implicit weight bias). Participants with moderate weight bias provided less specific feedback to students with overweight (vs. participants with high/low weight bias)

Findings suggested that many participants had concerns regarding their body weight and shape as well as weight bias
Investigated pre-service 226 pre-service teachers, ages health and weight-related issues
*BMI

*Body Satisfaction Scale

*Health promotive behaviors

*Weight control behaviors

*Weight IAT

*Healthy Lifestyle for University Students

*Qualitative interviews 
Table 1 (continued)

\begin{tabular}{|c|c|c|c|c|c|}
\hline $\begin{array}{l}\text { Ref. } \\
\text { No. }\end{array}$ & Authors & Study purpose & Sample & Methods/measures & Summary of findings \\
\hline & $\begin{array}{l}\text { Varea and } \\
\text { Underwood, } \\
2016\end{array}$ & $\begin{array}{l}\text { Explored weight bias } \\
\text { among PE pre-service } \\
\text { teachers }\end{array}$ & $\begin{array}{l}14 \text { pre-service teachers, ages } \\
18-26\end{array}$ & & $\begin{array}{l}\text { Themes emerged whereby } \\
\text { participants believed weight is an } \\
\text { indicator of health, is an } \\
\text { individual responsibility, is } \\
\text { controllable, and that it is } \\
\text { dangerous to normalize } \\
\text { overweight/obesity. Participants } \\
\text { expressed a desire to help } \\
\text { students with overweight/obesity, } \\
\text { regardless of whether or not their } \\
\text { help is sought }\end{array}$ \\
\hline [64] & $\begin{array}{l}\text { Russell-Mayhew } \\
\text { et al., } 2012\end{array}$ & $\begin{array}{l}\text { Assessed the } \\
\text { effectiveness of an } \\
\text { intervention targeting } \\
\text { weight-related } \\
\text { attitudes and beliefs }\end{array}$ & 14 pre-service $\mathrm{PE}$ teachers & $\begin{array}{l}\text { Intervention: 3-h educational } \\
\text { workshop } \\
\text { *Body Satisfaction Scale } \\
\text { *Eating Attitudes Test } \\
\text { *Sociocultural Attitudes Towards } \\
\text { Appearance Questionnaire } \\
\text { *Weight control behaviors } \\
\text { *Written qualitative feedback }\end{array}$ & $\begin{array}{l}\text { A decrease in disordered eating } \\
\text { attitudes pre-to-post intervention. } \\
\text { Qualitative analyses of participant } \\
\text { responses indicated an increased } \\
\text { awareness of weight-related } \\
\text { issues and concerns related to } \\
\text { incorporating information into PE } \\
\text { instruction }\end{array}$ \\
\hline [64] & $\begin{array}{l}\text { Russell-Mayhew } \\
\text { et al., } 2015\end{array}$ & $\begin{array}{l}\text { Assessed the } \\
\text { effectiveness of an } \\
\text { intervention targeting } \\
\text { weight-related } \\
\text { attitudes and beliefs }\end{array}$ & $\begin{array}{l}30 \text { pre-service elementary } \\
\text { teachers }\end{array}$ & $\begin{array}{l}\text { Intervention: } 3 \text {-h educational } \\
\text { workshop } \\
\text { *Weight IAT } \\
\text { *Body Satisfaction Scale } \\
\text { *Anti-Fat Attitudes Scale } \\
\text { *Eating Attitudes Test } \\
\text { *Teaching self-efficacy }\end{array}$ & $\begin{array}{l}\text { A significant decrease in implicit } \\
\text { and explicit weight bias following } \\
\text { the intervention, an increase in } \\
\text { body satisfaction, and an increase } \\
\text { in self-efficacy to address } \\
\text { weight-related issues }\end{array}$ \\
\hline [65] & $\begin{array}{r}\text { Tingstrom and } \\
\text { Nagel, } 2017\end{array}$ & $\begin{array}{l}\text { Examined the impact of } \\
\text { a brief obesity } \\
\text { awareness } \\
\text { intervention on } \\
\text { weight bias }\end{array}$ & $\begin{array}{l}50 \text { pre-service } P E \text { teachers } \\
\quad\left(M_{\text {age }}=24\right)\end{array}$ & $\begin{array}{l}\text { Participants were assigned to an } \\
\text { intervention or control group } \\
\text { *Anti-Fat Attitudes Scale } \\
\text { *Expectations and Abilities } \\
\text { Questionnaire }\end{array}$ & $\begin{array}{l}\text { Results suggested that participants in } \\
\text { the intervention group had } \\
\text { significantly decreased weight } \\
\text { bias following the 1-h } \\
\text { intervention }\end{array}$ \\
\hline
\end{tabular}

Sample population ages and grades were provided, when possible

Impact of Weight Bias on Students' Health and Well-being Five studies investigated the impact of weight-based victimization on students with regard to physical and psychological well-being $[8,32-34,35 \bullet]$. Results from these studies indicated that, within K-12 schools, children and adolescents who experienced weight-based teasing felt self-conscious, angry, and unappreciated by their peers as well as had low selfesteem and increased symptoms of depression compared to peers who were not teased for their weight $[8,32,33]$. Weight-based victimization was also associated with a variety of positive (e.g., seeking social support, utilization of stress reduction strategies) and negative (e.g., disengagement, avoidance, confrontation) coping strategies [34] in these settings. Within postsecondary education, a sample of medical students with overweight/obesity who perceived experiences of weight discrimination reported lower overall health, lower body esteem, and greater loneliness, and were more likely to report using drugs or alcohol as a coping strategy compared to medical students without overweight/obesity [35•].

Weight-Based Victimization Support Two studies examined children and youth preferences for support related to weight- based victimization [36, 37]. In a study about preferred sources of support, youth indicated they would most want their friends to intervene (66\%), followed by their peers $(58 \%)$, teachers $(55 \%)$, physical education teachers $(44 \%)$, and parents (43\%) [37]. Another study examined the perspectives of children, school staff, and parents to identify schoolbased support strategies, including creating a school environment that (1) discourages bullying, and promotes (2) social support, (3) self-esteem, and (4) healthy eating and regular physical activity for children of all sizes [36].

Experiences with Weight Bias in K-12 Physical Education Two papers examined the impact of weight bias on experiences within PE in K-12 schools. Wiltshire, Lee, and Evans' [38] qualitative study found that students did not want to "stand out as the bigger one" (p. 553) and that their engagement was dependent upon physical ability. Students with obesity who were regarded as good at sports, by self or others, engaged in activity at school, while those not regarded as good at sports did not [38]. One study retrospectively investigated childhood experiences of $\mathrm{PE}$ among a sample of adults who identified as having overweight/obesity [39]. Qualitative interviews were 
conducted with 15 adults, from which themes emerged related to participant's perceived inability to form positive relationships with their bodies in PE, as well as experiences of shame associated with public weighing in PE classes.

Student Weight Bias Reduction Intervention One study investigated the effects of a weight bias reduction intervention conducted among a sample of grade 4-6 students aimed at preventing weight-based teasing as well as unhealthy weight-control behaviors [40]. This multi-faceted intervention included an after-school program and theater program, as well as school and family environment components, and led to decreased reports of weight-based teasing among students.

\section{Teacher $(n=16)$ and Pre-Service Teacher $(n=11)$ Samples}

Papers included in this section are comprised of samples of both currently practicing (i.e., in-service) as well as preservice teachers. Although pre-service teachers are also postsecondary students, they were examined in their capacity as future teachers (e.g., attitudes toward students, perceptions of student ability). Thus, these studies are presented alongside investigations of currently practicing teachers in relation to weight bias. Research with teachers and pre-service teachers examined attitudes and behaviors toward students with obesity generally as well as specific to perceptions of academic ability. A few studies tested interventions aimed at reducing weight bias of current and future teachers.

Teacher Attitudes Twelve studies investigated teacher attitudes toward students with obesity, their perceptions of student ability, or their attitudes toward weight-related bullying policies [14, 41-43, 44• , 45, 46-48, 49•, 50, 51]. Results from these studies indicated the presence of explicit and implicit weight bias among non-specialist as well as PE teachers [41, 46], as well as the belief that children with obesity are a burden and have control over their body weight [51]. Martinez-Lopez et al. [47] found that teachers having higher perceived selfefficacy in fostering participation among students with overweight/obesity also had more positive attitudes toward these students. Despite evidence of weight bias among teachers, Puhl et al. [49] found that teachers recognized weight-based bullying as an issue and supported bullyingrelated prevention and intervention policies.

Researchers examining the influence of obesity on teacher's perceptions of academic ability found that teachers rated children with normal weight as having above-average abilities [50] whereas students with obesity were more likely to be perceived as having academic challenges [45]. Researchers also found that girls with obesity were perceived as having lower reading ability while boys with obesity were perceived as having lower math ability [44•]. Researchers also found that PE teachers had lower physical expectations for students with overweight/obesity [43] and perceived them to have poorer physical abilities [48]. Finally, researchers have looked at the influence of weight bias in a postsecondary setting. In an experimental investigation of the impact of body weight on graduate school admission decisions by faculty members, researchers found that having a high BMI was associated with fewer offers of admission, especially among female applicants [14]. In another study, PE faculty members indicated a willingness to have students with obesity within their program, but did not believe that a physical educator with obesity would be a positive role model for students [42].

Teacher Behavior Two studies investigated classroom behavior or behavioral intentions toward students with obesity $[52,53]$. After engaging in field observations and interviews with PE teachers, researchers observed that students with overweight were regarded as different, were provided with individualized goals, and were perceived as a challenge to teachers [52]. In an experimental investigation, it was found that PE teachers were more likely to intervene in an instance of bullying for a female student with overweight compared to a female student without overweight, and that there were no differences in likelihood of intervention for male students [53].

Pre-Service Teacher Attitudes Eight studies investigated attitudes of pre-service teachers toward child or adolescent students with obesity [56-63]. Studies with both a general sample of pre-service teachers $[56,62]$ and samples of PE preservice teachers $[49 \bullet, 63]$ have reported implicit and explicit weight bias in these samples. In qualitative research, PE preservice teachers described the belief that weight is a proxy for health, that body weight is within individual control, and indicated a desire to assist students with obesity with weight loss [63]. When comparing the attitudes of PE pre-service teachers with non-specialist pre-service teachers or non-education postsecondary students, researchers have found that weight bias exists among all samples, but that pre-service teachers with a PE specialty display higher weight bias compared to non-PE teachers [57] or non-education postsecondary students [60] as well as significantly lower expectations for students with obesity [58]. Muller et al. [59] conducted an experimental investigation of the impact of information related to weight on the judgments of 57 pre-service teachers about students' academic and social skills. Contrary to previous research, the results of this study suggested that pre-service teachers perceived children and youth with overweight as having better academic skills than non-overweight students and similar social skills as non-overweight students [59].

Intervention Research Five studies reported on the results of weight bias reduction interventions, three with pre-service teachers [64-66], one with a mixed sample of pre-service 
and in-service teachers [54], and one with a sample of teachers and health professionals [55]. After receiving a 3-h intervention, pre-service teachers specializing in PE reported an increased awareness of weight bias, but were concerned with how to incorporate information about body image into their instruction [66]. After a similar 3-h intervention, elementary specialist pre-service teachers reported a significant decrease in both implicit and explicit weight bias as well as a significant increase in perceived self-efficacy in addressing weightrelated content in their instruction [64]. In another sample of pre-service teachers, Tingstrom and Nagel [65] conducted a 1 -h intervention that included information about environmental influences on weight, weight bias, and positive teaching strategies, which corresponded to a significant decrease in explicit weight bias. Following an online module promoting body size acceptance, pre-service students and teachers both reported a decrease in explicit weight bias [54]. Finally, among a sample of teachers and health professionals, participants taking part in an intervention promoting a view of health as occurring at any body size improved their awareness of weight bias and improved self-efficacy to address weight bias in schools [55].

\section{Discussion}

Weight bias in educational settings has the potential to significantly impact individuals' well-being and educational experiences. The studies reviewed herein reinforce the existence of weight bias within educational settings among children, adolescents, and teachers as well as among future teachers. Specifically, our review showed that students in K-12 schools frequently experience weight bias in multiple forms from peers in all spaces within schools. In samples of teachers and pre-service teachers, our review showed that negative attitudes toward students with obesity are pervasive and negatively impact perceptions of student ability. While emerging, intervention research has provided positive results among samples of K-12 students, teachers, and pre-service teachers.

\section{Future Research Directions}

The results of this review highlight a need for researchers to place greater emphasis on expanding weight bias research in several underexamined areas. Weight bias with pre-service and in-service teacher populations is well established as well as within the K-12 student population. However, more evidence that weight bias is carried from the K-12 settings into the educational experiences of postsecondary students is needed. More knowledge on the factors that impact weight bias in teachers in general, as well as PE teachers specifically, is necessary to better understand the nature of weight bias in these populations [51]. A better understanding of weight bias among teachers will provide the opportunity for more effective weight bias reduction interventions to be developed for this population. Additionally, although the incidence of weight bias among students is well established, more research is needed to understand potential contributing factors to weight bias in educational settings (e.g., BMI screenings [67]) and obesity prevention programs in schools [68].

Our review indicated a lack of research examining weight bias reduction interventions with students, teachers, and preservice teachers, with existing research limited to small sample sizes. Addressing weight bias in K-12 and postsecondary educational settings brings with it unique challenges, such as creating developmentally appropriate interventions that can be implemented to meet multiple needs (i.e., curricula) within the limitations of existing policies and practices (i.e., school bullying legislation). In addition, interventions may be most effective when they are tailored to the institution in which they are implemented, meaning additional research needs to investigate how efforts might be individualized to meet the needs of a variety of different settings. Finally, interventions are most likely to be successful if they enlist the support of various stakeholders (i.e., adolescents who live with obesity) by employing a community-based, student-oriented research approach [69].

Finally, our review highlighted methodological limitations of research in this area. The majority of research conducted to date has been with cross-sectional samples with descriptive, correlational, or qualitative data. While these studies have provided valuable information regarding the impact of weight bias on the educational experiences of students, an increase in experimental and/or longitudinal research will help investigate educational disparities experienced by students with obesity. Further, most studies have primarily white participants and research with more diverse samples is needed to develop a better understanding of how weight bias impacts the educational experiences of students from various racial, ethnic, and other diverse backgrounds.

\section{Limitations}

Although this review highlighted the impact of weight bias in educational settings, not all aspects of weight bias or weight-related issues were captured. For example, this review did not examine differences in academic achievement based on body weight, which has been examined in a previous review [20]. Future research should examine if negative attitudes toward students with obesity influence educational attainment and contribute to inequity over time in educational settings. This review also did not examine variables that could be related to weight bias such as the impact of thinideal internalization, disordered eating practices, and other weight-related attitudes, which have been shown 
to negatively impact the educational experiences of students of all sizes [70].

\section{Conclusion}

It is important to gain a greater understanding of the occurrence and impacts of weight bias in educational settings in the short and long term, and the factors that contribute to and sustain weight bias among students and teachers, as well as interventions to reduce or prevent it. Further research in this area will continue to establish weight bias as a social justice issue to be addressed within educational settings [71]. Reducing weight bias is critical to creating educational environments wherein students and teachers of all sizes are embraced and experience equitable treatment necessary for success.
Acknowledgements SN is currently funded by a Doctoral Research Award from the Social Sciences and Humanities Research Council at the University of Calgary. ASA acknowledges support from her Chercheur Boursier Junior 1 Award (no. 35277) from les Fonds de Recherche du Québec- Santé at Concordia University, Montreal, Quebec, as well as Banting Postdoctoral Fellowship Award from the Canadian Institutes of Health Research.

\section{Compliance with Ethical Standards}

Conflict of Interest Sarah Nutter, Alana Ireland, Angela S. Alberga, Isabel Brun, Danielle Lefebvre, K. Alix Hayden, and Shelly RussellMayhew declare they have no conflict of interest.

Human and Animal Rights and Informed Consent This article does not contain any studies with human or animal subjects performed by any of the authors.

\section{Appendix}

Table 2 Weight bias in educational settings: MEDLINE Search Strategy. Database(s): Epub Ahead of Print, In-Process and Other Non-Indexed Citations, Ovid MEDLINE(R) Daily and Ovid MEDLINE(R) 1946 to December 2016

\begin{tabular}{|c|c|c|c|c|}
\hline Concepts & No. & Searches & Results & Annotations \\
\hline Weight bias/stigma & $\begin{array}{l}1 \\
2 \\
3 \\
4 \\
5 \\
6 \\
7 \\
8 \\
9 \\
10 \\
11 \\
12 \\
13 \\
14 \\
15 \\
16 \\
17 \\
18 \\
19 \\
20 \\
21 \\
22 \\
23 \\
24 \\
25 \\
26 \\
27 \\
28 \\
29 \\
30 \\
31 \\
32 \\
33 \\
34 \\
35 \\
36 \\
37 \\
38\end{array}$ & 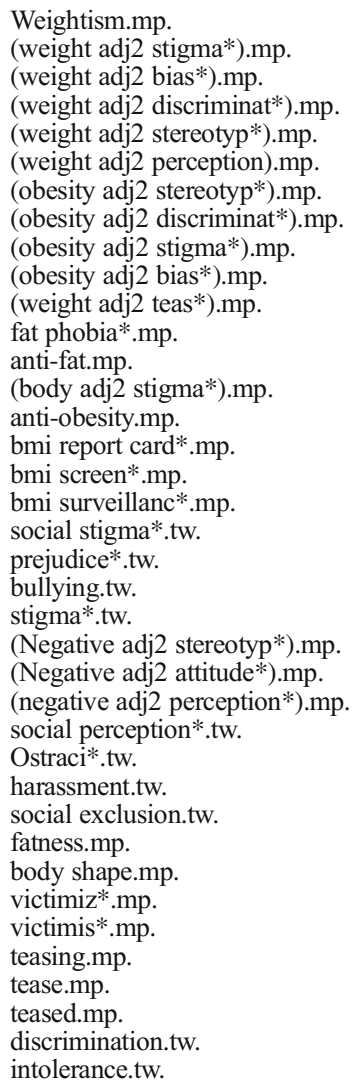 & $\begin{array}{r}2 \\
228 \\
328 \\
193 \\
29 \\
1152 \\
23 \\
45 \\
146 \\
75 \\
161 \\
61 \\
115 \\
51 \\
5835 \\
10 \\
90 \\
16 \\
1428 \\
4993 \\
3616 \\
27,465 \\
822 \\
5489 \\
2139 \\
1038 \\
492 \\
2677 \\
1240 \\
3938 \\
2489 \\
7172 \\
488 \\
1090 \\
951 \\
1002 \\
99,852 \\
29,733\end{array}$ & $\begin{array}{l}\text { - Search uses } M P \text { for sensitivity, searching more } \\
\text { broadly for the keyword } \\
\text { - Search uses } T W \text { for specificity of search } \\
\text { for keywords that may result in less precision } \\
\text { if searched in } M P \text { (all) fields } \\
\text { - TW = title/abstract } \\
\text { - ADJ (adjacency) searches for words adjacent to } \\
\text { each other (proximity searching), in either } \\
\text { direction. } \\
\text { Expands keyword search } \\
\text { - Subject headings are used for each concept, } \\
\text { indicated by a/at the end of the search phrase } \\
\text { - For each subject heading, the tree (subject } \\
\text { heading hierarchy) } \\
\text { was explored to determine whether } \\
\text { or not to explode the subject heading } \\
\text { (i.e., include narrower terms) } \\
\text {-For sensitivity, a majority of subject headings } \\
\text { were not exploded }\end{array}$ \\
\hline
\end{tabular}


Table 2 (continued)

\begin{tabular}{|c|c|c|c|c|}
\hline Concepts & No. & Searches & Results & Annotations \\
\hline & 39 & Prejudice/ & 25,785 & \\
\hline & 40 & social stigma/ & 4325 & \\
\hline & 41 & stereotyping/ & 10,603 & \\
\hline & 42 & shame/ & 2016 & \\
\hline & 43 & Bullying/ & 2376 & \\
\hline & 44 & Social Perception/ & 21,475 & \\
\hline & 45 & exp Social Isolation/ & 16,168 & \\
\hline & 46 & Weight Perception/ & 660 & \\
\hline & 47 & or $/ 1-46$ & 252,659 & \\
\hline \multirow[t]{16}{*}{ Overweight/obesity } & 48 & underweight.tw. & 8431 & \\
\hline & 49 & overweight.tw. & 57,140 & \\
\hline & 50 & obese.tw. & 110,383 & \\
\hline & 51 & obesity.tw. & 198,810 & \\
\hline & 52 & thinness.tw. & 2245 & \\
\hline & 53 & body mass index.tw. & 150,522 & \\
\hline & 54 & bmi.tw. & 113,835 & \\
\hline & 55 & body weight.tw. & 180,204 & \\
\hline & 56 & Obesity/ & 165,854 & \\
\hline & 57 & Obesity, Morbid/ & 15,113 & \\
\hline & 58 & Body Weight/ & 184,563 & \\
\hline & 59 & Overweight/ & 20,203 & \\
\hline & 60 & Pediatric Obesity/ & 3806 & \\
\hline & 61 & body mass index/ & 112,889 & \\
\hline & 62 & Thinness/ & 5227 & \\
\hline & 63 & or/48-62 & 706,284 & \\
\hline \multirow[t]{37}{*}{ Education } & 64 & peer*.tw. & 69,281 & - Keywords and subject headings for \\
\hline & 65 & student*.tw. & 230,703 & children/adolescents were not searched as, \\
\hline & 66 & teacher*.tw. & 39,047 & when included, the search results became \\
\hline & 67 & professor*.tw. & 26,819 & very large, and when reviewed, \\
\hline & 68 & instructor*.tw. & 6726 & largely irrelevant \\
\hline & 69 & educator*.tw. & 23,468 & \\
\hline & 70 & college*.tw. & 97,956 & \\
\hline & 71 & university.tw. & 290,704 & \\
\hline & 72 & faculty.tw. & 38,571 & \\
\hline & 73 & educational institution.tw. & 320 & \\
\hline & 74 & graduate school*.tw. & 998 & \\
\hline & 75 & classroom*.tw. & 13,805 & \\
\hline & 76 & elementary.tw. & 23,315 & \\
\hline & 77 & middle school*.tw. & 4889 & \\
\hline & 78 & junior high.tw. & 2244 & \\
\hline & 79 & high school*.tw. & 27,950 & \\
\hline & 80 & kindergarten*.tw. & 5689 & \\
\hline & 81 & $\mathrm{k}-12 . \mathrm{tw}$ & 8811 & \\
\hline & 82 & k-16.tw. & 166 & \\
\hline & 83 & higher education.tw. & 9497 & \\
\hline & 84 & post secondary.tw. & 535 & \\
\hline & 85 & pupil*.tw. & 25,933 & \\
\hline & 86 & postsecondary.tw. & 753 & \\
\hline & 87 & education.tw. & 374,387 & \\
\hline & 88 & preschool*.tw. & 25,017 & \\
\hline & 89 & school*.tw. & 247,895 & \\
\hline & 90 & grade.tw. & 275,359 & \\
\hline & 91 & grades.tw. & 46,213 & \\
\hline & 92 & exp Peer Group/ & 18,637 & \\
\hline & 93 & Education/ & 20,865 & \\
\hline & 94 & Education, Graduate/ & 5363 & \\
\hline & 95 & exp Schools, Nursery/ & 1477 & \\
\hline & 96 & Students/ & 47,590 & \\
\hline & 97 & Teaching/ & 47,158 & \\
\hline & 98 & Schools/ & 32,433 & \\
\hline & 99 & Universities/ & 36,034 & \\
\hline & 100 & or/64-99 & $1,461,730$ & \\
\hline Combining 3 concepts & 101 & 47 and 63 and 100 & 2812 & \\
\hline English limit & 102 & Limit 101 to english language & 2660 & \\
\hline Year limit & 103 & Limit 102 to yr. $=" 2000$-Current" & 2363 & \\
\hline \multirow{7}{*}{$\begin{array}{l}\text { Excluding specific types of } \\
\text { publications }\end{array}$} & 104 & Limit 103 to (addresses or autobiography or bibliography & 6 & \\
\hline & & or biography or & & \\
\hline & & $\begin{array}{l}\text { clinical conference or congresses } \\
\text { or dataset or dictionary or directory or lectures or }\end{array}$ & & \\
\hline & & news or newspaper article or & & \\
\hline & & patient education handout & & \\
\hline & & $\begin{array}{l}\text { or periodical index or personal narratives or portraits } \\
\text { or video-audio media or webcasts) }\end{array}$ & & \\
\hline & 105 & 103 not 104 & 2357 & \\
\hline
\end{tabular}

Search annotation based on recommendations from: [72] 
Publisher's Note Springer Nature remains neutral with regard to jurisdictional claims in published maps and institutional affiliations.

\section{References}

Papers of particular interest, published recently, have been highlighted as:

- Of importance

1. Goodman N, Dornbusch SM, Richardson SA, Hastorf AH. Variant reactions of physical disabilities. Am Sociol Rev. 1963;28:429-35. https://doi.org/10.2307/2090353.

2. Puhl RM, Latner JD. Stigma, obesity, and the health of the nation's children. Psychol Bull. 2007;133:557-80. https://doi.org/10.1037/ 0033-2909.133.4.557.

3. Richardson SA, Goodman N, Hastorf AH, Dornbusch SM. Cultural uniformity in reaction to physical disabilities. Am Sociol Rev. 1961;26:241-7. https://doi.org/10.2307/2089861.

4. Bromfield PV. Childhood obesity: psychosocial outcomes and the role of weight bias and stigma. Educ Psychol Pract. 2009;25:193209. https://doi.org/10.1080/02667360903151759.

5. Puhl RM, Latner JD, O'Brien K, Luedicke J, Forhan M, Danielsdottir S. Cross-national perspectives about weight-based bullying in youth: nature, extent and remedies. Pediatr Obes. 2016;11:241-50.

6. Shetgiri R. Bullying and victimization among children. Adv Pediatr Infect Dis. 2013;60:33-51. https://doi.org/10.1016/j.yapd.2013.04. 004.

7. Puhl RM, Luedicke J, Heuer C. Weight-based victimization toward overweight adolescents: observations and reactions of peers. J Sch Health. 2011;81:696-703. https://doi.org/10.1111/j.1746-1561. 2011.00646.x

8. Puhl RM, Luedicke J. Weight-based victimization among adolescents in the school setting: emotional reactions and coping behaviors. J Youth Adolesc. 2012;41:27-40. https://doi.org/10.1007/ s10964-011-9713-Z.

9. Fox CL, Farrow CV. Global and physical self-esteem and body dissatisfaction as mediators of the relationship between weight status and being a victim of bullying. J Adolesc. 2009;32:1287-301. https://doi.org/10.1016/j.adolescence.2008.12.006.

10. Neumark-Sztainer D, Falkner N, Story M, Perry C, Hannan PJ, Mulert S. Weight-teasing among adolescents: correlations with weight status and disordered eating behaviors. Int J Obes Relat Metab Disord. 2002;26:123-31. https://doi.org/10.1038/sj.ijo. 0801853.

11. Latner JD, Stunkard AJ. Getting worse: the stigmatization of obese children. Obes Res. 2003;11:452-6. https://doi.org/10.1038/oby. 2003.61.

12. Russell-Mayhew S, Grace A. A call for social justice and best practices for the integrated prevention of eating disorders and obesity. Eat Disord. 2015;24:54-62. https://doi.org/10.1080/10640266. 2015.1113829 .

13. Lumeng J, Forrest P, Appugliese D, Kaciroti N, Corwyn R, Bradley $\mathrm{R}$. Weight status as a predictor of being bullied in third through sixth grades. Pediatrics. 2010;125:E1301-7. https://doi.org/10. 1542/peds.2009-0774.

14. Burmeister JM, Kiefner AE, Carels RA, Musher-Eizenman DR. Weight bias in graduate school admissions. Obesity. 2013;21: 918-20. https://doi.org/10.1002/oby.20171

15. Pont SJ, Puhl R, Cook SR, Slusser W, Section on Obesity, the Obesity Society. Stigma experienced by children and adolescents with obesity. Pediatrics. 2017;140(6):e20173034.
16. Bauer KW, Yang YW, Austin SB. "How can we stay healthy when you're throwing all of this in front of us?" Findings from focus groups and interviews in middle schools on environmental influences on nutrition and physical activity. Health Educ Behav. 2004;31(1):34- 46.

17. Christensen S. Weight bias and stigma in children. J Pediatr Surg. 2018;7:72-4. https://doi.org/10.1097/JPS.0000000000000178.

18. Gray WN, Kahan NA, Janicke DM. Peer victimization and pediatric obesity: a review of the literature. Psychol Sch. 2009;46:720-7. https://doi.org/10.1002/pits.20410.

19. Li W, Rukavina P. A review on coping mechanisms against obesity bias in physical activity/education settings. Obes Rev. 2009;10:8795. https://doi.org/10.1111/j.1467-789X.2008.00528.x.

20. Martin A, Booth JN, McGeown S, Niven A, Sproule J, Saunders $\mathrm{DH}$, et al. Longitudinal associations between childhood obesity and academic achievement: systematic review with focus group data. Curr Obes Rep. 2017;6:297-313. https://doi.org/10.1007/s13679017-0272-9.

21. Higgins JPT, Green S. Cochrane handbook for systematic reviews of interventions Version 5.1.0 (updated March 2011). The Cochrane Collaboration; 2011. Available from http://handbook.cochrane.org.

22. Moher D, Liberati A, Tetzlaff J, Altman DG. Preferred reporting items for systematic reviews and meta-analyses: the PRISMA statement. Ann Intern Med. 2009;151:264-9. https://doi.org/10.1371/ journal.pmed1000097.

23. Alberga AS, Pickering B, Hayden A, Ball G, Edwards A, Jelinski S, et al. Weight bias reduction in health professionals: a systematic review. Clin Obes. 2016;6:175-88. https://doi.org/10.1111/cob. 12147.

24. Puhl RM, Brownell KD. Bias, discrimination, and obesity. Obes Res. 2001;9:788-805. https://doi.org/10.1038/oby.2001.108.

25. Puhl RM, Heuer CA. The stigma of obesity: a review and update. Obesity. 2009;17:941-64. https://doi.org/10.1038/oby.2008.636.

26. Bacchini D, Licenziati MR, Garrasi A, Corciulo N, Driul D, Tanas $\mathrm{R}$, et al. Bullying and victimization in overweight and obese outpatient children and adolescents: an Italian multicentric study. PLoS One. 2015;10:1-13. https://doi.org/10.1371/journal.pone.0142715.

27. Crosnoe R, Frank K, Mueller A. Gender, body size and social relations in American high schools. Soc Forces. 2008;86:1189216. https://doi.org/10.1353/sof.0.0004.

28. Cunningham SA, Vaquera E, Long JL. Race, ethnicity, and the relevance of obesity for social integration. Ethn Dis. 2012;22: 317-23.

29. Kahle L, Peguero AA. Bodies and bullying: the interaction of gender, race, ethnicity, weight, and inequality with school victimization. Vict Offenders. 2017;12:323-45. https://doi.org/10.1080/ 15564886.2015 .111755$.

30. Puhl RM, Peterson JL, Luedicke J. Weight-based victimization: bullying experiences of weight loss treatment-seeking youth. Pediatrics. 2013;131:e1-9. https://doi.org/10.1542/peds.20121106.

31. Zeller MH, Reiter-Purtill J, Ramey C. Negative peer perceptions of obese children in the classroom environment. Obesity. 2008;16: 755-62. https://doi.org/10.1038/oby.2008.4.

32. Lampard A, MacLehose M, Eisenberg R, Neumark-Sztainer F, Davison M. Weight-related teasing in the school environment: associations with psychosocial health and weight control practices among adolescent boys and girls. J Youth Adolesc. 2014;43: 1770-80. https://doi.org/10.1007/s10964-013-0086-3.

33. Li W, Rukavina P. The nature, occurring contexts, and psychological implications of weight-related teasing in urban physical education programs. Res Q Exerc Sport. 2012;83:308-17. https://doi.org/ $10.1080 / 02701367.2012 .10599862$.

34. Li W, Rukavina P, Wright P. Coping against weight-related teasing among adolescents perceived to be overweight or obese in urban 
physical education. J Teach Phys Educ. 2012;31:182-99. https:// doi.org/10.1123/jtpe.31.182.

35. Phelan SM, Burgess DJ, Puhl R, Dyrbye LN, Dovidio JF, Yeazel $\mathrm{M}$, et al. The adverse effect of weight stigma on the well-being of medical students with overweight or obesity: findings from a national survey. J Gen Intern Med. 2015;30:1251-8. https://doi.org/ 10.1007/s11606-015-3266-x. One of the few studies to investigate the educational experience of individuals with obesity at a postsecondary level.

36. Haines J, Neumark-Sztainer D, Thiel L. Addressing weight-related issues in an elementary school: what do students, parents, and school staff recommend? Eat Disord. 2007;15:5-21. https://doi. org/10.1080/10640260601044428.

37. Puhl RM, Peterson JL, Luedicke J. Strategies to address weightbased victimization: youths' preferred support interventions from classmates, teachers, and parents. J Youth Adolesc. 2013;42:31527. https://doi.org/10.1007/s10964-012-9849-5.

38. Wiltshire G, Lee J, Evans J. "You don't want to stand out as the bigger one": exploring how PE and school sport participation is influenced by pupils and their peers. Phys Educ Sport Pedagog. 2017;22:548-61. https://doi.org/10.1080/17408989.2017. 1294673.

39. Sykes H, McPhail D. Unbearable lessons: contesting fat phobia in physical education. Sociol Sport J. 2008;25:66-96. https://doi.org/ 10.1123/ssj.25.1.66.

40. Haines J, Neumark-Sztainer D, Perry CL, Hannan PJ, Levine MP. VIK (very important kids): a school-based program designed to reduce teasing and unhealthy weight-control behaviors. Health Educ Res. 2006;21:884-95. https://doi.org/10.1093/her/cyl123.

41. Fontana FE, Furtado O, Marston R, Mazzardo O, Gallagher J. Antifat bias among physical education teachers and majors. Phys Educ. 2013;70:15-31. https://doi.org/10.1177/1356336X16643304.

42. Fontana F, Furtado O Jr, Mazzardo O Jr, Hong D, de Campos W. Anti-fat bias by professors teaching physical education majors. Eur Phys Educ Rev. 2017;23:127-38. https://doi.org/10.1177/ $1356336 \times 16643304$.

43. Greenleaf C, Weiller K. Perceptions of youth obesity among physical educators. Soc Psychol Educ. 2005;8:407-23. https://doi.org/ 10.1007/s11218-005-0662-9.

44. Kenney EL, Gortmaker SL, Davison KK, Austin SB. The academic penalty for gaining weight: a longitudinal, change-in-change analysis of BMI and perceived academic ability in middle school students. Int J of Obes. 2015;39:1408-13. https://doi.org/10.1038/ijo. 2015.88. One of the few longitudinal research studies examining weight bias in education.

45. Kenney EL, Redman MT, Criss S, Sonneville KR, Austin SB. Are K-12 school environments harming students with obesity? A qualitative study of classroom teachers. Eat Weight Disord. 2017;22: 141-52. https://doi.org/10.1007/s40519-016-0268-6.

46. Lau PWC, Leung BWC, Pitkethly AJ, Ransdell L. Do physical education teachers and general teachers differ in their implicit anti-fat bias? Int J Phys Educ. 2018;1:27-38.

47. Martínez-López EJ, Grao-Cruces A, Zamora-Aguilera N, De la Torre-Cruz MJ. The association between Spanish physical education teachers' self-efficacy expectations and their attitudes toward overweight and obese students. J Teach Phys Educ. 2017;36:22031. https://doi.org/10.1123/jtpe.2014-0125.

48. Peterson JL, Puhl RM, Luedicke J. An experimental assessment of physical educators' expectations and attitudes: the importance of student weight and gender. J Sch Health. 2012;82:432-40. https:// doi.org/10.1111/j.1746-1561.2012.00719.x.

49. Puhl RM, Neumark-Sztainer D, Bryn Austin S, Suh Y, Wakefield DB. Policy actions to address weight-based bullying and eating disorders in schools: views of teachers and school administrators. J Sch Health. 2016;86:507-15. https://doi.org/10.1111/josh.12401.
One of the few studies to investigate support for policies to reduce weight bias in schools among educators.

50. Shackleton NL, Campbell T. Are teachers' judgements of pupils' ability influenced by body shape? Int J Obes. 2014;38:520-4. https://doi.org/10.1038/ijo.2013.210.

51. Wilson SM, Smith AW, Wildman BG. Teachers' perceptions of youth with obesity in the classroom. Adv School Ment Health Promot. 2015;8:231-43. https://doi.org/10.1080/1754730X.2015. 1074054.

52. Doolittle SA, Rukavina PB, Li W, Manson M, Beale A. Middle school physical education teachers' perspectives on overweight students. J Teach Phys Educ. 2016;35:127-37. https://doi.org/10. 1123/jtpe.2014-0178.

53. Peterson JL, Puhl RM, Luedicke J. An experimental investigation of physical education teachers' and coaches' reactions to weightbased victimization in youth. Psychol Sport Exerc. 2012;13:17785. https://doi.org/10.1016/j.psychsport.2011.10.009.

54. Hague AL, White AA. Web-based intervention for changing attitudes of obesity among current and future teachers. J Nutr Educ Behav. 2005;37:58-66. https://doi.org/10.1016/S1499-4046(06) 60017-1.

55. McVey G, Gusella J, Tweed S, Ferrari M. A controlled evaluation of web-based training for teachers and public health practitioners on the prevention of eating disorders. Eat Disord. 2009;17:1-26. https://doi.org/10.1080/10640260802570064.

56. Glock S, Beverborg AOG, Müller BCN. Pre-service teachers' implicit and explicit attitudes toward obesity influence their judgments of students. Soc Psychol Educ. 2016;19:97-115. https://doi.org/10. 1007/s11218-015-9315-9.

57. Greenleaf C, Martin SB, Rhea D. Fighting fat: how do fat stereotypes influence beliefs about physical education? Obesity. 2008;16: S53-9. https://doi.org/10.1038/oby.2008.454.

58. Lynagh M, Cliff K, Morgan PJ. Attitudes and beliefs of nonspecialist and specialist trainee health and physical education teachers toward obese children: evidence for "anti-fat" bias. J Sch Health. 2015;85:595-603. https://doi.org/10.1111/josh.12287.

59. Müller BCN, Beverborg AOG, Glock S. Pre-service teachers' academic judgments of overweight students. Soc Psychol Educ. 2017;20:897-913. https://doi.org/10.1007/s11218-017-9400-3.

60. O'Brien KS, Hunter JA, Banks M. Implicit anti-fat bias in physical educators: physical attributes, ideology and socialization. Int J Obes. 2007;31:308-14. https://doi.org/10.1038/sj.ijo.0803398.

61. Readdy T, Wallhead TL. Manifestation of anti-fat bias in preservice physical education teachers. Phys Educ. 2016;73:450-70. https:// doi.org/10.18666/TPE-2016-V73-13-5954.

62. Tkachuk M, Russell-Mayhew S. Health and weight beliefs and behaviours of pre-service teachers: considerations and implications for a health promotion perspective. Alberta J Educ Res. 2017;63: 286-303.

63. Varea V, Underwood M. 'You are just an idiot for not doing any physical activity right now': pre-service health and physical education teachers' constructions of fatness. Eur Phys Educ Rev. 2016;22:465-78. https://doi.org/10.1177/1356336X15617446.

64. Russell-Mayhew S, Nutter S, Ireland A, Gabriele T, Bardick A, Crooks J, et al. Pilot testing a professional development model for preservice teachers in the area of health and weight: feasibility, utility, and efficacy. Adv School Ment Health Promot. 2015;8: 176-86. https://doi.org/10.1080/1754730X.2015.1040040.

65. Tingstrom CA, Nagel E. The impact of an obesity awareness intervention on anti-fat attitudes and expectations of preservice physical educators. Action Teach Educ. 2017;39:54-66. https://doi.org/10. 1080/01626620.2016.1245634.

66. Russell-Mayhew S, Ireland A, Peat G. The impact of professional development about weight-related issues for pre-service teachers: a pilot study. Alberta J Educ Res. 2012;58:314-29. 
67. Thompson HR, Madsen KA. The report card on BMI report cards. Curr Obes Rep. 2017;6:163-7. https://doi.org/10.1007/s13679017-0259-6.

68. Lee HY, Lee EL, Pathy P, Chan YH. Anorexia nervosa in Singapore: an eight-year retrospective study. Singap Med J. 2005;46:275-81.

69. Russell-Mayhew S, Ireland A, Murray K, Alberga AS, Nutter S, Gabriele T, et al. Reflecting and informing a culture of wellness: the development of a comprehensive school health course in a bachelor of education program. J Educ Thought. 2017;50:156-81.

70. Breithaupt L, Eickman L, Byrne CE, Fischer S. Enhancing empowerment in eating disorder prevention: another examination of the
REbeL peer education model. Eat Behav. 2017;25:38-41. https:// doi.org/10.1016/j.eatbeh.2016.05.003.

71. Nutter S, Russell-Mayhew S, Arthur N, Ellard JH. Weight bias as a social justice issue: a call for dialogue. Can Psychol. 2018;59:8999. https://doi.org/10.1037/cap0000125.

72. Cooper C, Dawson S, Peters J, Varley-Campbell J, Cockcroft E, Hendon J, et al. Revisiting the need for a literature search narrative: A brief methodological note. Res Synth Methods. 2018;9(3):36136. 